\title{
Seasonal patterns in the developmental rate of glochidia in the endangered thick-shelled river mussel, Unio crassus Philipsson, 1788
}

\author{
Katarzyna Zając $\cdot$ Tadeusz A. Zając
}

Received: 1 October 2019/Revised: 5 March 2020/Accepted: 23 March 2020/Published online: 18 May 2020

(C) The Author(s) 2020

\begin{abstract}
Females of freshwater mussels spawn eggs which, after fertilization, are brooded until the developing larvae reach a stadium ready to infest a fish host in order to complete the obligate parasitic phase of their life. We investigated the duration of the brooding period in the endangered thick-shelled river mussel Unio crassus in two rivers in southern Poland and identified the stadia of glochidia development which could be used to assess current larval developmental stages. The eggs were fertilized in marsupia. The duration of the brooding period shortened significantly during the season, from 35 days in early spring to 9 days in summer. The break between consecutive broods was usually short but very variable: from almost no break to 17 days. $20 \%$ of brooding events inspected every other day were miscarried at different stadia of larval development. The recorded differences in brooding time may significantly influence the reproductive output of individuals and populations, depending on the thermal conditions, which may be affected by both anthropogenic impact and global climate change. The study offers a practical
\end{abstract}

Guest editors: Manuel P. M. Lopes-Lima, Nicoletta Riccardi, Maria Urbanska \& Ronaldo G. Sousa / Biology and Conservation of Freshwater Molluscs

K. Zając $\cdot$ T. A. Zając $(\bowtie)$

Institute of Nature Conservation, Polish Academy of Sciences, Al. A. Mickiewicza 33, 31-120 Kraków, Poland

e-mail: tzajac@iop.krakow.pl scheme for assessing female gravidity advancement in Unio crassus, which may be very informative for the future application of conservation measures in this endangered European species.

Keywords Freshwater mussels $\cdot$ Conservation biology · Ontogeny · Phenology · Global warming · Water temperature

\section{Introduction}

Probably the most important ecological factor attracting the attention of scientists is global warming: for obvious reasons this is expected to influence the physiological processes and ontogeny of organisms. In the case of unionid mussels, however, little can at present be said about the possible impacts of temperature changes, because knowledge of their ontogeny remains far from satisfactory. The species of Unionidae produce large quantities of larvae called glochidia, which, to complete their development, need an obligatory phase of parasitic life, attached to fish gills or fins (Modesto et al., 2018). The probability of fish infestation determines a population's prospects (Ćmiel et al., 2019); however, the factors influencing glochidia production are still poorly understood. It has been demonstrated that temperature influences the timing of glochidia release (Gascho Landis et al., 2012; Schneider et al., 2018) and that elevated water 
temperatures negatively influence the survival of glochidia, though not of juveniles (Pandolfo et al., 2010). Taeubert et al. (2014) showed that temperature can speed up the parasitic phase in U. crassus; one can therefore predict that it will also accelerate glochidia development.

The rate of larval development is also of some practical importance for both ecological studies and specific conservation actions. Researchers and practitioners should have schemes to hand for assessing female gravidity advancement, the stadium of glochidia development and the overall duration of glochidia brooding (Beaty \& Neves, 2004; Gascho Landis et al., 2012; see also the system proposed for M. margaritifera by Scheder et al., 2011). For planning conservation actions, it is important to know when glochidia development is fast or slow during the season. It is also important to correctly interpret glochidium morphology when evaluating developmental advancement, because glochidial maturity is crucial for the success of artificial cultures of juvenile mussels (Jones et al., 2005 and references therein). A description of the developmental mode provides information on the evolution of this form of larva (Barnhart et al., 2008). This could be useful in those aspects of research in which glochidium morphology is important, e.g. taxonomy (Kennedy \& Haag, 2005), environmental studies of habitat quality (e.g. Hansten et al., 1996; Wang et al., 2007) or paleoenvironmental reconstructions (Brodniewicz, 1968; Aldridge \& Horne, 1998).

From the methodological point of view, ecological studies or conservation actions need a different approach to glochidia development from that adopted in embryology. Embryological papers on the early stages of larval development in Mollusca are usually based on cross-sections of fixed tissues (e.g. Chumnanpuen et al., 2011) or focus on specific aspects of development (Kurita et al., 2009; Hinzmann et al., 2013). Although these procedures perfectly elucidate the problems addressed, they are not easily adapted to ecological studies or conservation actions, because they need sophisticated and time-consuming tissue preparation and are therefore unsuitable for taking ad hoc decisions regarding procedures, e.g. for assessing glochidia development in the field. Once devised, however, a ready scheme of larval development provides useful insight into developmental processes and makes for the easier interpretation of field observations of developing glochidia in other species as well (Wassing \& Southgate, 2012).

Populations of unionids have been severely affected by anthropogenic factors in Europe during the recent period of intensive economic development. One of the most threatened species from this group is the thick-shelled river mussel Unio crassus. Once one of the most numerous and widespread species of large freshwater mussels, it is now in rapid decline, even though it is protected by EU law (Habitat Directive) and is the subject of numerous conservation programmes (Lopes-Lima et al., 2017). In this paper we show the general pattern of glochidia development, identify easily recognizable stages of their ontogenic development, and measure the development time from egg production to glochidia release, as well as the break needed for the development of the next brood; finally, we test the influence of time during the season on developmental rates.

\section{Methods}

Study sites

The studies were conducted in 2015-2016 and in 2018-2019 in the River Biała (49.860523, 21.034322; near Lubaszowa), and in 2015 and 2016 in the River San (49.197347, 22.682157; near Procisne); both rivers are in southern Poland. The rivers harbour the two most abundant Polish populations of $U$. crassus; these two environments differ, however, which is why were chosen for this study.

The Biała is a typical river of the Carpathian foothills, flowing northwards out of the Beskid Niski range down to the valley of the River Vistula (Wisła). Draining an area of $983 \mathrm{~km}^{2}$ (quite highly populated), it has a channel length of $101.8 \mathrm{~km}$ and channel width from ca 15 (incised) to $50 \mathrm{~m}$ (braided). The Biała flows through areas of sedimentary rocks known as Carpathian Flysch, transporting large amounts of fine sediments. At low water, the channel is characterized by a pool-riffle structure. The area lies within the 'Biała Tarnowska' Natura 2000 site (PLH120090). In the Polish monitoring scheme (Zajacc, 2010), this population of $U$. crassus has been accorded favourable (FV) status and its density locally exceeds 1500 ind./ $100 \mathrm{~m}$ channel section, with very good recruitment. 
The San is a typical natural mountain river with a plane bed, ca $30 \mathrm{~m}$ wide, constrained by the geological structure of the hills. The bed substrate is partly bare rock and partly rock debris and gravel, with low sandy banks covered with Carex fusca and $C$. silvatica. The river bed is shallow ( $<30 \mathrm{~cm}$ depth at the usual water level). The estimated population of $U$. crassus in the studied river section is ca 30000 individuals. The area lies within the 'Bieszczady' Natura 2000 site (PLC 180001), and this section of the river drains water from protected areas of the Bieszczady National Park. In the Polish monitoring scheme, the population of $U$. crassus from the San has favourable (FV) status, with an average density reaching as high as 3048 ind./ $100 \mathrm{~m}$ channel section, with very good recruitment.

\section{Glochidia development}

In this paper we use the following terms: "spawning" describes the transfer of eggs from the gonads to the marsupia; "brooding event" is a particular case of eggs spawned by a particular female, followed by a "brooding period" when they are developing in the marsupia of that female, now gravid, until "glochidia release" (the emptying of the marsupia, the final release of all, fully-grown glochidia into the water); " 1 st, 2nd, 3rd,..., Nth brood" are successive brooding events of the same female; "miscarriage" is the premature evacuation of underdeveloped embryos from the marsupia.

In 2015 and 2016, just after ice melting, when the mussels appeared on the surface of the sediments covering the channel banks, 134 (2015) and 131 (2016) individuals were collected in the Biała and 130 (2015) and 145 (2016) in the San. They were marked with an alphanumeric code engraved in the periostracum with a DREMEL microdrill, then released back into the river. Every week in the Biała and every 2 weeks in the San, the marked mussels were searched for and gathered in a pail. Their marsupia were immediately sampled by puncturing them with a needle; after sampling they were returned to the same place in the river. The tiny fragments of marsupium content were at once inspected under a microscope and described in the database. All the photographs in Fig. 1. were taken directly in the field during the marsupia inspection. Whenever the water level was too high to safely enter the channel, the survey was postponed until the water level had fallen. Both rivers are fed by water flowing down from mountains, so this delay was usually no longer than 3 days. The gonads of 3 females chosen at random from the pail were punctured during spring surveys (from 1 April to 7 July 2015) with a syringe to inspect the gonad contents. The needle was inserted into the mussel's food, the liquid contents being extracted to the syringe and immediately examined on a glass slide under a microscope for the presence of sperm or oocytes.

The duration of glochidia development was estimated in two ways:

(1) Non-intensive intervention regime. The marsupia of particular individuals were examined once a week (the Biała) or once every 2 weeks (the San) throughout the season. It was assumed that if glochidia development was fast, marsupia filled with developing glochidia should be found during one survey, but if the developmental time was longer, then marsupia should be found filled with embryos during two, three or even four surveys. Only evident cases were taken into consideration in the analysis, i.e. when the sequence of embryonic developmental stages during the consecutive inspections conformed to the sequence of typical embryonic development from egg to glochidium, as illustrated by Lillie (1895). Thus, if we take the number of surveys to be a measure of the duration of glochidia development, females should be found gravid in a larger number of surveys early in the season (cold water) and in a smaller number of surveys later in the season (warm water).

(2) Intensive intervention regime, i.e. glochidia development during the season was examined more frequently. In 2018 we sampled the mussels and examined their marsupia every other day. Mussel sampling began during ice melting in the Biała river (Lubaszowa site). Initially, the sample consisted of 66 individuals, of which 24 females were gravid with the earliest stages of glochidia development (eggs or initial cleavage). The number of gravid females subsequently increased to 38 as new females spawned eggs. After 14 April we enlarged the sample of gravid females to $N=46$, collecting females which were in the process of releasing glochidia. They were easy 


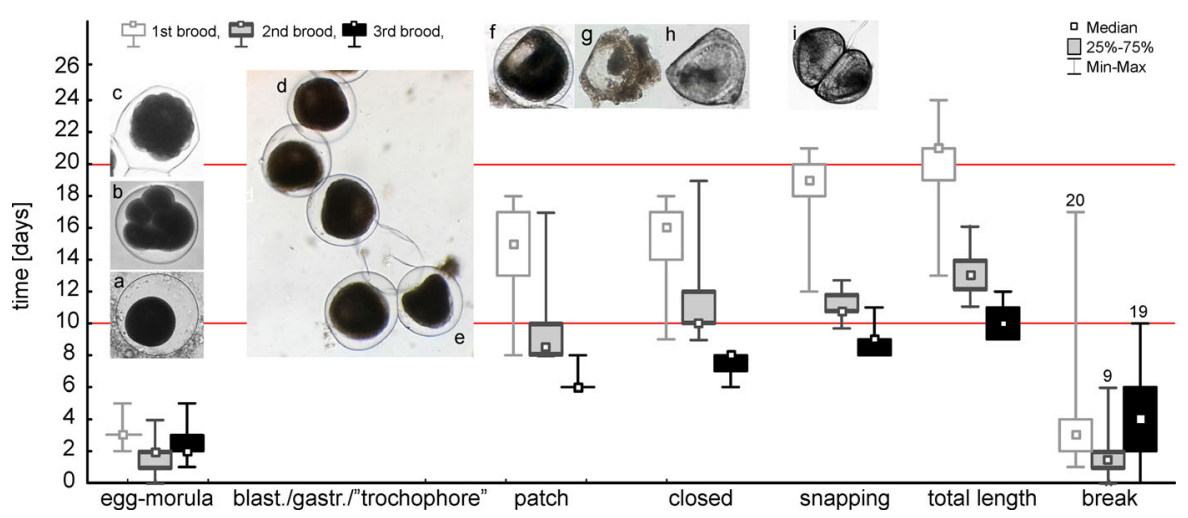

Fig. 1 The rate of development of glochidia, expressed as the median duration of each stadium of that development, measured during every other glochidia inspection day, and the length of the break between consecutive broods in the River Biała in 2018 for 37 individuals in the first, 20 in the second, and 43 in the June brood, for which the exact spawning date was known and the duration of development of particular stages could be measured: (a) unfertilized egg, (b) 4 cell stage, (c) morula with two macromeres, (d) blastula/gastrula stages, (e) trochophore-like

to find, because glochidia release behaviour in Unio crassus is very distinctive: females with fully-grown glochidia migrate to the water margins at the banks, from where they eject jets of water up to $1 \mathrm{~m}$ back into the channel. The spurted water carries glochidia and attracts host fishes (Aldridge et al., 2018). In this way, having found females right at the end of the previous brooding period, we had the opportunity to measure the length of the break between the initial and the subsequent broods ("break 1") and to capture very precisely the onset of second broods, thereby acquiring a full record of the development of two consecutive broods. All the females were inspected every other day until 12 May, which also allowed us to measure "break 2 " following the completion of the second brood. The third survey of glochidia development in 2018 was conducted between 7 and 20 June, after the water temperature had become stable. If there was a break during the June sampling period, that is, if some marked individuals ended the previous brood and started the next one during that period, it was referred to as "break 3". We differentiated between "terminated breaks", i.e. breaks which started after the release of glochidia of the previous brood and terminated when the eggs were spawned in the stage, (f) early shell formation "patch" stage, (g) late shell formation "bearded" stage, (h) closed glochidium "D-stage", (i) open snapping glochidium with protruding larval thread; no data are shown for the blastula/gastrula/trochophore stage because its assessment is prone to errors in the accurate recognition of the stage; for the break duration sample sizes are shown above the bars; the small square represents the median, the box indicates quartiles, and the whiskers show the range of dates for a given number of surveys

next one, from "non-terminated breaks", which were breaks without a specified beginning or end (which lasted from an unknown point in time when the inspection of mussels started during the ongoing glochidia brooding, or the breaks did not end with the next brood onset within the period of study).

In general, the early embryonic development stages were classified according to Lillie (1895): (1) Egg (Fig. 1a) or initial cleavage with a record of the number of visible cells (Fig. 1b) and the general morphology of the embryo, especially macromeres and micromeres, thereafter morula as long as the two macromeres (Fig. 1c) were still easily distinguishable at small magnification. (2) The next class of embryonic development consisted of three stages: the blastula, gastrula and early "trochophore-like" stages. Because distinguishing them was problematic, we combined them into one class (Fig. 1d, e), without analysing their development time. The blastula is usually a spherical layer of cells (the blastoderm) surrounding a fluid-filled cavity (the blastocoel). It is still of the same size, encapsulated in the former egg membrane. In field conditions, the blastula and gastrula can be distinguished by the presence of an empty blastocoel and the invagination of the blastoderm, which defines the gastrula. But much depends on the orientation of the cells towards the observer: the 
gastrula seen from the side opposite to the invagination will give a picture similar to blastula, and the same applies to the later stages of the rounded embryo; even the cone-shaped trochophore-like stages can be perceived as spheres. This can lead to errors (see also Lillie (1895): "the endoderm generally assumes the form of a sac, communicating by the blastopore with the exterior, but at other times no lumen is discernible"). For the later stages we defined our own typology, based on easy-to-identify stages, when (3) a transparent patch of developing shell began to appear within the triangular-shaped embryo (Fig. 1f), when (4) the glochidium had achieved its final shape but was closed (Fig. 1h), and when (5) the glochidium was open, making snapping valve movements, and bore a larval thread, usually protruding outside the open shell (Fig. 1i). During the examination of marsupia, the sampled embryos were placed in a given developmental category on the basis of the developmental stage of the majority of embryos visible under the microscope. The duration of the embryo stages could be recorded only for those broods in which spawned eggs were observed within the sample (sometimes mixed with the earliest stages of cleavage) or if in the preceding survey the female was not gravid, i.e. neither eggs nor embryos were present in the marsupia.

Miscarriage of the brood was identified on the basis of the developmental sequence: if a female spawned eggs in the marsupia, which subsequently developed according to the sequence described above, but then at some moment during the examination every other day the marsupium was found to be empty before the embryos had reached the snapping glochidia stage, such a brooding event was identified as miscarried.

The measurements of developmental time in glochidia were repeated in 2019, under different thermal conditions (Fig. 2) and within a non-intensive intervention regime. The first brood was studied just after ice melting (9 March), whereas examination of the June brood started on 22 June. To avoid brood miscarriages, mussels were inspected once in order to identify females with eggs. Among the identified gravid females, only 7 were identified which had been retrieved in the 2018 sample. For these 7 females we had a full record (from eggs or eggs with initial cleavage to snapping glochidia) for the first broods in both 2018 and 2019. To increase the 2019 sample we marked and investigated an additional 15 wild females with eggs in their marsupia. After the initial inspection to identify eggs, the females were left undisturbed until the 20th day after fertilization, after which they were inspected at two-day intervals in order to capture the precise day of glochidial maturity. A similar methodology was adopted in June 2019, when spurting females with snapping glochidia were identified; these were left undisturbed until the next inspection series started after the 8th day, repeated every 2 days, until all the females released glochidia.

Water temperatures were measured each year using two HOBO dataloggers. These were installed on 6 March 2018 and 9 March 2019 in the water in the same channel section but on opposite banks during the first instances of ice breaking.

\section{Statistical analyses}

We analysed only individuals for which we had a full record of breeding during the season. The relation between the number of inspections in which female gravity was observed as a response variable, in relation to time during the season, with controlled influence of year and individual ID was analysed in SPSS GLZ: Generalized Linear Mixed Models. Because the mussels in the San were inspected once every 2 weeks, the response variable was binominal, analysed with a logit link function against the date of brood initiation, influence of year and individual mussel ID as a random factor. The mussels in the Biała were inspected every week, so the response variable (number of inspections) had a Poisson distribution analysed with a log link function against the same set of predictors. A similar analysis was applied to the duration of the break between consecutive broods. The break duration in 2018 as a response variable was compared between terminated and non-terminated breaks for the three types of broods analysed (first, second and the June broods, Fig. 2) with the controlled influence of the spawning date and individual mussel ID as a random factor. The remaining analyses were simple comparisons, conducted with standard tests.

\section{Results}

Spawning and fertilization

In the River Biała, spawning started on 22 March 2015, 29 March 2016, 31 March 2018 and 15 March 


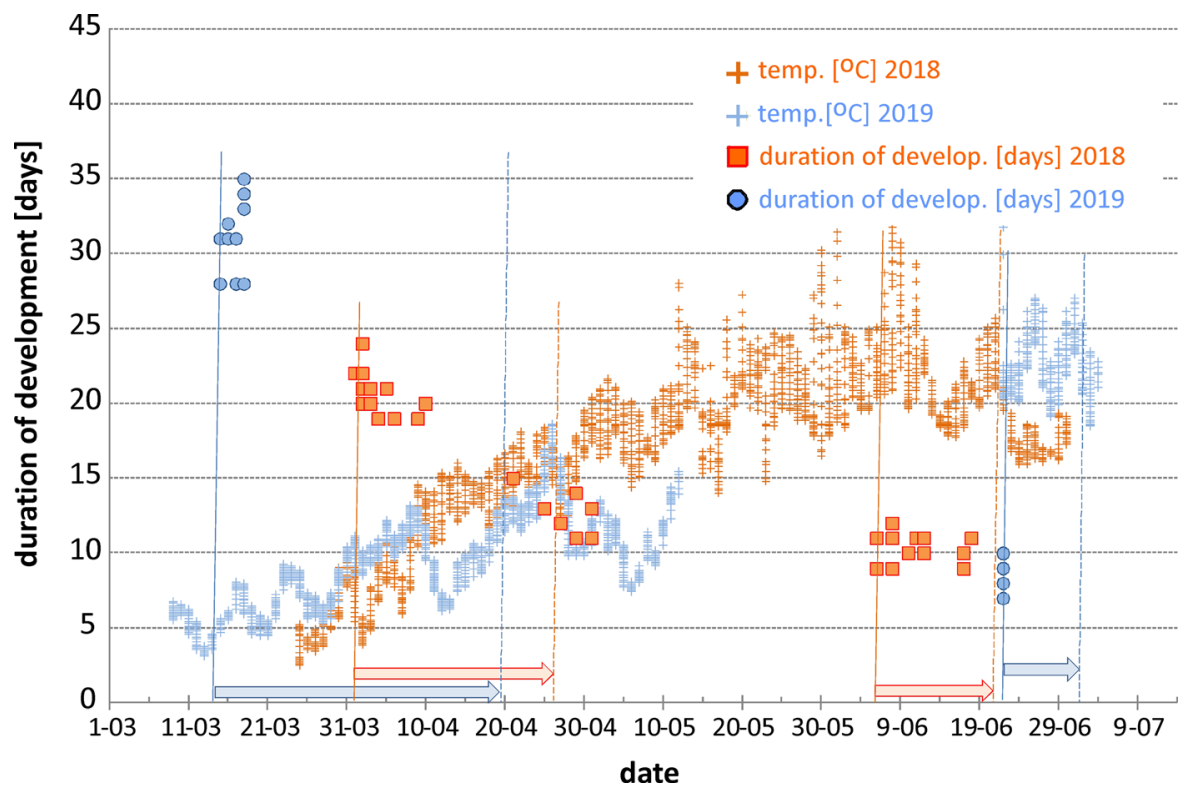

Fig. 2 The length of glochidia brooding periods in different broods (first, second, June brood) during the season vs water temperature during the same periods; the data for 2018 are

2019. The earliest spawning in the San was recorded on 11 April in 2015 and on 27 March in 2016.

In the Biała in 2015, not a single gonad contained fertilized eggs in the 37 females whose gonads were sampled by puncturing during the reproduction period. During the whole season, samples of glochidia $(N=1473)$ were taken from gravid females' marsupia (on average, $82(\mathrm{SD}=32)$ individuals were retrieved and examined in each survey). Unfertilized eggs were recorded in the marsupia of five individuals during the first survey; some of them had a small admixture of zygotes cleaving into two cells (three individuals). In the next survey, four of these females were retrievedtheir marsupia were found to contain developing embryos. During the first survey in 2016, 15 samples (out of 1150) taken from gravid females (on average 72 (SD = 11) ind.) contained unfertilized eggs: seven contained exclusively unfertilized eggs, while the other eight contained eggs with different proportions (from single to ca 20\%) of fertilized ones, cleaving into 2-4 cell embryos. During the next survey, 12 of those females were again retrieved-their marsupia were found to contain only developing embryos. On 27 April 2016 numerous spermatozeugmates were observed (Fig. 3A) in the pail where the mussels had been collected for inspection. presented in red, those from 2019 in blue, the circles and squares indicate the egg spawning dates, the broad arrows indicate the median duration of development on the date axis

During the first survey in 2018, we found six females in the Biała whose marsupia were filled exclusively with unfertilized eggs at the beginning of the first brood, with no cleaving cells; one sample consisted of eggs with a few two-cell stadium embryos. By the time of the next survey, all of them had become $4-8$ cell embryos. During the second brood, only one marsupium filled with eggs was found, along with a few two-cell embryos. The initial stages of development were taking place faster during the second brood: in one survey we found that the marsupia of 21 females were empty, but during the next survey that they were filled with $2-4$ cell stage embryos, without any unfertilized eggs. During the June broods, only two females were found with their marsupia filled exclusively with unfertilized eggs; in one case, the next survey revealed eggs with an admixture of early embryos (from the two-cell to the early morula stage), whereas the other revealed a stage with uniform blastomeres.

In the River San, examination of gravid female marsupia in 2015 (on average 59 ( $\mathrm{SD}=15$ ) females retrieved per survey) revealed that out of a total of 479 samples taken during the whole season, the marsupium contained unfertilized eggs in six cases. Just one of these samples contained exclusively 

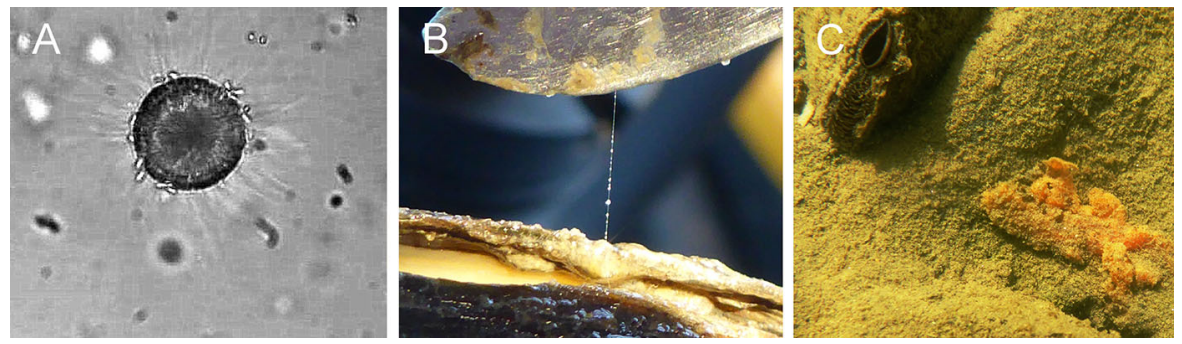

Fig. 3 A Photograph of a spermatozeugmate observed in the River Biała during the surveys, B larval threads visible to the naked eye, C aborted conglutinate (the orange structures against the background of the grey-brown silt)

unfertilized eggs, while the other five contained 2-4 cell embryos; all of these broods developed further into embryos. In 2016, 11 of the 1263 samples taken from an average of 105 individuals $(S D=30)$ per survey contained marsupia with unfertilized eggs: four contained exclusively unfertilized eggs, the others had eggs with an admixture of 2-4 stage embryos. During the next survey, eight samples contained only developing embryos in later stages. On 2 days in 2015 (25 April and 23 May) spermatozeugmates were observed in the pails containing the mussels kept for examination. Gonad puncturing during 2015-2016 revealed that in the San not a single gonad contained fertilized eggs from the 34 females sampled between 11 April and 23 May 2015 and from the 52 females sampled between 7 April and 7 May 2016.

Developmental rate during the season

The duration of embryonic development, estimated on the basis of weekly surveys, was longer in the earliest broods than in the broods raised late in the season in the Biała (Fig. 4A, GLZ with mussel ID as a random factor: $F=1.93, \mathrm{df}_{1}=25, \mathrm{df}_{2}=238, P=0.006$ ), with no significant influence of year $(F=0.15$, $\left.\mathrm{df}_{1}=1, \mathrm{df}_{2}=238, P=0.70\right)$. The fortnightly surveys in the San yielded similar relations: development was the slowest in the earliest broods and the fastest in the broods raised late in the season (Fig. 4B; GLZ: $\left.\mathrm{F}=27.8, \mathrm{df}_{1}=1, \mathrm{df}_{2}=104, P<0.0001\right)$, with no influence of year $\left(F=1.10, \mathrm{df}_{1}=1, \mathrm{df}_{2}=104\right.$, $P=0.751)$. The proportions of the developmental stadia recorded during inspections of marsupia did not differ between the two rivers (Fig. 5A, $\chi^{2}=0.08$, df $=4, P=0.99)$.

The much more detailed examination of larval development in gravid females during 2018 revealed that the onset of reproduction could be easily identified by the presence of unfertilized eggs (Fig. 1a), as well as during the earliest cleavage into two cells or the very characteristic stage of four cells of unequal size (one macromere and three micromeres, resembling a little "foot", Fig. 1b). The last stage of embryonic development, indicating the recent onset of breeding, that was still readily discernible, was when all the blastomeres were large enough to be easily distinguished from each other, with two characteristic, clearly visible and disproportionately large macromeres (Fig. 1c). The earliest stages of larval development, i.e. unfertilized eggs and cleavage, were short, their median duration being 3 days in the earliest broods and 2 days in the later ones, although the maximum duration could be as long as 5 days. The timings of the later blastula/gastrula/early trochophore phases (Fig. 1d, e) were not estimated because the results were encumbered by the large error in distinguishing between blastula, gastrula and trochophore in field conditions. The next easily identifiable stage was the laterally compressed, triangular embryo, with shell development leading to a very characteristic transparent "patch" (Fig. 1f), enlarging during the following days. The cells surrounding the developing shell (forming a kind of "beard" around the shell edge, Fig. 1g), disappeared at that time; finally, the clear shell of the closed glochidium appeared (D-stage, Fig. 1h). The glochidium opened after 2-3 days, snapped spontaneously, and the protruding larval thread became visible (Fig. 1i). After 1 day in most cases, but sometimes after as many as 3 days, the fullygrown glochidia were released during the spurting process.

Although difficult to determine in field conditions, the conical "trochophore-like" stage (Fig. 1e), directly preceding the "patch" stadium (Fig. 1f), 


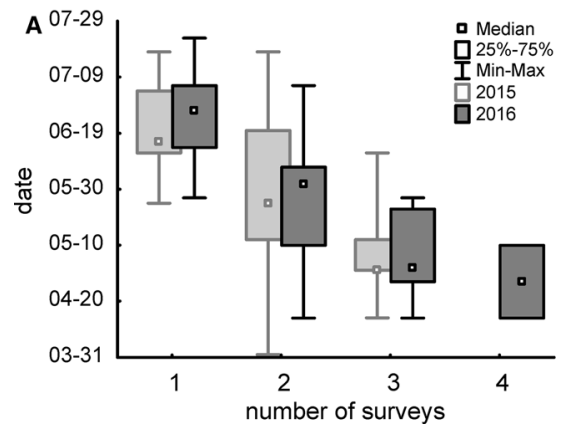

Fig. 4 Relationship between time during the season and the rate of development of glochidia expressed by the number of surveys during which females were found gravid; females were sampled every week in the River Biała (A) and every 2 weeks in

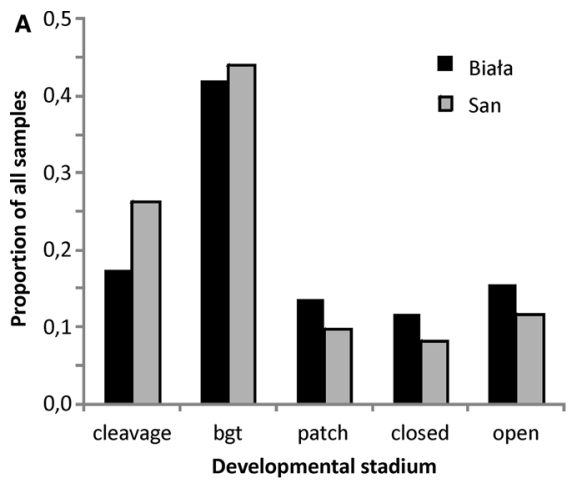

Fig. 5 Comparison of the proportion of developmental stages between the two rivers sampled (A; pooled for both years of the study), and comparison of frequency of miscarriage among the

indicated roughly the half-way point in development. The embryo was usually observed within the egg capsule in earlier stages of development (Fig. 1a-f). The last stage of development, the open glochidium (Fig. 1i), was actually sharply defined: the opening of the glochidia must have been quite a rapid process as we never observed any intermediate stages. Identification of fully-grown glochidia in $U$. crassus was further facilitated because the larval threads, visible even with the naked eye, could be extruded from the marsupium with a pointed tool (Fig. 3B).

In 2018, the total period of larval development in the river Biała, counting from egg spawning to the final spurting, was 20 days during the first brood in early spring (within the temperature range $4-13.5^{\circ} \mathrm{C}$ ), shortening to 11 days in late spring (second brood: $\left.1-18.5^{\circ} \mathrm{C}\right)$ and 10 days in the June brood $\left(19-25^{\circ} \mathrm{C}\right.$; Fig. 2). During the first brood, the total period of larval development decreased both with date during the

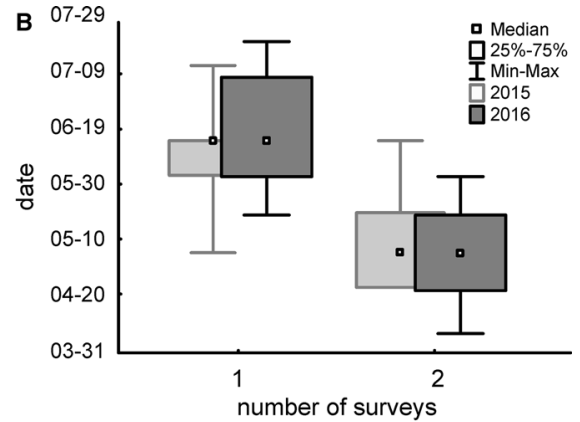

the River San (B); the small square represents the median, the box indicates the quartiles, and the whiskers show the range of dates for a given number of surveys

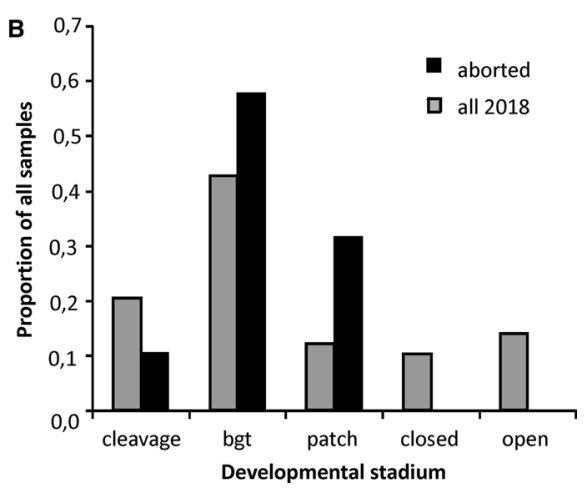

broods studied in detail in the River Biała in 2018, in relation to the frequency of developmental stages of glochidia, pooled for the both studied rivers (B)

season (Spearman's rank correlation coefficient $r_{\mathrm{S}-}$ $=-0.74, N=17, P=0.0007)$ and in relation to the daily median temperature $\left(r_{\mathrm{S}}=-0.67, P=0.003\right)$. During the second brood there was no correlation between the total period of larval development, and date $\left(r_{\mathrm{S}}=-0.57, N=9, P=0.11\right)$ and temperature $\left(r_{\mathrm{S}}=-0.15, N=9, P=0.69\right)$; the same applied to the June brood (date: $r_{\mathrm{S}}=0.16, N=24, P=0.44$, temperature: $r_{\mathrm{S}}=-0.05, N=24, P=0.82$ ). The total duration of development was significantly different between successive broods of the same individuals. The Wilcoxon matched pairs test showed that the first brood differed significantly from both the second $(Z=2.9, N=11, P=0.003)$ and the June $(Z=2.5, N=8, P=0.012)$ brood; the second brood, too, differed significantly from the June brood $(Z=2.8, N=11, P=0.005)$. A similar comparison of median temperatures for the same periods of glochidia brooding also revealed significant 
differences (Kruskal-Wallis test: $H_{2,51}=41.8$, $P<0.0001)$ : the first brood was not significantly different from the second one $(P=0.065)$, but the third was significantly different from the first $(P=0.019)$ and second $(P \ll 0.0001)$ ones.

In 2019, glochidia development during the first brood also took much longer than during the June broods; more importantly, it lasted much longer than during the first broods in 2018 (Fig. 2); in 2019 the maximal recorded brooding time was 39 days, even the minimal recorded time (28 days) was longer than the longest brooding time in 2018. Comparison of the females for which we had complete records in 2018 and in 2019 revealed significant differences both for paired comparisons of the same individuals $\left(X_{2018}=19.8, \mathrm{SD}=0.69, X_{2019}=35.7, \mathrm{SD}=1.70\right.$; the Wilcoxon matched pairs test: $Z=2.37, N=7$, $P=0.018$ ), and for all the wild individuals inspected (Kruskal-Wallis test: $H_{1,33}=24.3, \quad P<0.0001$ ). Comparison of the developmental periods of glochidia between the June broods of $2018\left(\mathrm{X}_{2018}=10.00\right.$, $\mathrm{SD}=0.91$, min. $=9)$ and $2019\left(X_{2019}=9.89, \mathrm{SD}=\right.$ 1.54 , min. $=8)$ revealed no statistically significant differences (Kruskal-Wallis test: $H_{1,39}=0.12$, $P=0.73$ ).

The break between consecutive broods in 2018 was usually short but also very variable (Fig. 1). When the break duration in 2018 was compared between terminated and non-terminated breaks, between the first, second and June broods, with the controlled influence of spawning date and individual mussel ID, it appeared that the only significant difference (GLM: $F(1,50)=11.8, P=0.002)$ was in the duration of the break between the terminated and non-terminated breaks. Because the length of the non-terminated breaks was not confined, the lengths of terminated broods were shorter than shown in Fig. 1: the median length of a terminated break after the first brood was $\mathrm{Md}=3$ days (from 1 to 17 days); during the second broods $\mathrm{Md}=1$ (from 0 to 5 days), and during the June broods $\mathrm{Md}=2(0-5)$.

\section{Miscarriage}

Neither among gravid females, examined once a week in the Biała nor among those examined every 2 weeks in the San was a female ever observed to have expelled glochidia in the form of large conglutinates (Fig. 3C). We found this only in 2018, in females that were examined every other day in the Biała; by contrast, in a mussel bed consisting of ca 60 individuals, observed but not disturbed during each survey, no expelled conglutinates were ever found. Out of a total of 98 brooding events analysed in 2018, 19 (20\%) were miscarried at different stadia of larval development: 2 during cleavage, 11 during the blastula/gastrula/ trochophore stage and 6 during the patch stage. Comparison of the frequency of miscarriage at a given developmental stage with the general frequencies of developmental stages (pooled for both the Biała and the San) revealed no significant differences $\left(\chi^{2}=0.33\right.$, df $=4, P=0.99$, Fig. 5B). The number of miscarried brooding events did not differ among consecutive broods: 5 were lost from first broods, 8 from second broods and 6 from June broods. Miscarried conglutinates were observed on the river bed in close proximity to the mussels (Fig. 3C).

\section{Discussion}

\section{General biology}

The presence of unfertilized eggs in marsupia, which subsequently develop into next-stage embryos, suggests that fertilization in $U$. crassus takes place in the marsupia; however, the details of this process are unknown. The role of spermatozeugmates also remains unexplored. Even during the regular monitoring of reproduction in this species, they were found far too rarely for any meaningful conclusions to be drawn about their role and the ecological factors which give rise to them. Marsupia with unfertilized eggs were observed much more often during the onset of the first brood than of later ones, which could indicate that low temperatures slow down fertilization and development, thus increasing the likelihood of their being spotted during a given survey.

There are only a few papers documenting glochidium development (Wood, 1974; Scheder et al., 2011; Soliman et al., 2016). The very general mode of the early ontogenic development of $U$. crassus embryos conforms to published studies on Bivalvia (Raven, 1958; the best illustrated case study is that by Wassing $\&$ Southgate, 2012). However, it is surprising to see how rapid early development in the best studied marine bivalves is in comparison with our data. Of course, such a difference is by no means attributable to 
phylogenetic differences, although the impact of temperature must be suspected. One can compare the development of some early stages, similar in all Bivalvia, e.g. from fertilization to the onset of shell formation, when the early shell material forms a "saddle" structure over the trochophore-this is the stadium corresponding to the early shell stadium ("patch") in U. crassus. In Pteria penguin, studied by Wassing \& Southgate (2012; see also the references therein for other species), the period from fertilization to the onset of shell formation lasts for only 11-12 hpf, whereas in $U$. crassus it extends from 6 (in summer) to 15 days (in early spring, $5-10^{\circ} \mathrm{C}$ in Fig. 2). However, development lasting 12 days until the beginning of shell formation has been demonstrated in the deep-sea $(650 \mathrm{~m})$ cold-seep $\left(7-8^{\circ} \mathrm{C}\right)$ marine mussel "Bathymodiolus" childressi (Arellano \& Young, 2009).

The acceleration of glochidia development during spring seems to be proportional in all the developmental stages described (Fig. 1) except for the earliest ones (Fig. 1a-c), in which the proportion is large in relation to their developmental time (Fig. 5A). This could be explained on the basis of observations of marine mussels, the embryos of which stopped developing as a reaction to stress (salinity and high temperature) at the 2-4-8 cell stage, whereas under milder conditions they developed rapidly to the most advanced stages (Arellano \& Young, 2009). Similarly, this high proportion of early stages in U. crassus might be a reaction to some unfavourable ambient conditions; but this is a problem requiring further study.

Pinpointing the onset of reproduction (egg spawning) is very easy, because the mature eggs and early embryonic stages are highly characteristic (Fig. 1). While some stages (blastula-trochophore) are difficult to distinguish without adequate practice and highquality microscopes, not usually available in the field, the late stages of the developmental period are readily identifiable. In recent years, many low-cost, batterypowered, hand-held digital devices with an independent light source have become available. These enable a quite reliable identification of the characteristic developmental stages of glochidia. In this way, the stadium fully capable of infesting fish is readily identifiable in the field, facilitating the decision as to which gravid females should be collected (Ćmiel et al., 2018).
Most papers on unionid glochidia morphology concentrate on the morphology of the mature glochidium (e.g. Nezlin et al., 1994; Araujo \& Ramos, 1998), because the functional adaptations of the fully mature glochidium determine the ultimate fitness of individuals. However, this does not mean that knowledge about the earlier stages is unimportant: what a mature glochidium looks like is common knowledge, but the earlier stages remain unknown. This may cause difficulties in interpreting the current reproductive stage of an individual and may, for example, lead to excessive sampling of gravid females in order to increase the probability of obtaining fully-developed glochidia (O'Brien et al., 2013), or keeping gravid females too long in captivity, which may affect glochidia viability. Basic knowledge on the rate of development is also needed in other conservation measures, like the translocation of adults to seed new populations or restore past population ranges (Zajacc et al., 2018). Therefore, the ability to recognize crucial stages of glochidial development enabled by these (or similar) low-cost approaches are necessary, since this basic data on the phenology of glochidia development are fundamental for the conservation of these animals, both in the field and in captivity.

The mode of glochidia development is also important in environmental conservation practice, because mature glochidia are used for testing the toxicity of various chemical products (Bringolf et al., 2007). Hence, it is also important to know the stage of glochidial maturity in gravid females in order to obtain glochidia suitable for testing. Glochidia viability is usually tested with chemical stimuli (Jones et al., 2005) such as salt. Salt provokes a muscle contraction as a rigid chemical superstimulus (Holman, 1957). The identification of glochidial maturity can be done without salt, however, by observing them directly and especially their behaviour (spontaneous snapping), as is usually done for the foot movements of juvenile mussels (Wang et al., 2007). Glochidia with closed shells are frequently found together with open ones, they are regarded as dead, whereas in fact this is a normal physiological stage of the glochidium at a particular moment of its development (Fig. 1h). It should be remembered that closed glochidia are simply not mature and within a few days they will be functionally ready to infest fish. 
High and low temperature impacts

Temperature can influence the development rate of glochidia (Watters \& O'Dee, 2000; Hastie \& Young, 2003 and references therein), but the problem of the influence of temperature on the timing of glochidia release is still far from being explained (Watters \& O'Dee, 2000). There are studies focusing on the timing of glochidia release (Neves \& Widlak, 1988; Haggerty \& Garner, 2000; Culp et al., 2011), but complete studies of mussel phenology giving the timing of fertilization, glochidia development and their release (e.g. Weaver et al., 1991) are surprisingly rare. Studies of glochidia release are based on random samples of dissected individuals (e.g. Haggerty et al., 2005) or glochidia sampled from the water column (e.g. Hastie \& Young, 2003), so they usually reveal only the general timing and duration of the reproductive period within a season for a whole population.

In general, the date of glochidia release is a consequence of the egg spawning date. It is spawning that precedes and determines the date of glochidia release (all other things, like temperature, food, etc. being equal, of course), whereas the timing of egg spawning is not usually observed in detail and the factors initiating it are obscure. A mussel spawning just after ice melt does not have information on the environmental conditions that will prevail 1 month later, during glochidia release, especially if ambient conditions are highly variable. Consequently, the ultimate reproductive success of a spawning mussel will vary because of the unpredictability of the brooding and release conditions.

\section{High temperature impacts}

Here we demonstrate that ambient factors (indicated by time during the season and temperature) influence the period of glochidia development and that this shortens significantly during the season, by two-three times (from ca 30-20 days to 10 days) between the first broods and the June broods. As a rule, therefore, the timing and frequency of glochidia release change significantly during a season. April 2018 was the warmest such month in Poland since 1800 (meteomodel.pl). In the following year, temperatures were much lower (Fig. 2) and development rates slower compared with the previous year. The glochidia development period was in excess of one month, and thus was longer by one-third: a change of this magnitude cannot be neglected during conservation actions, because on the basis solely of experience from previous seasons, which, for example, were cold, one can overlook the period of maturity of glochidia in a warm season, when glochidia will be released earlier. In both years, however, the June rates of development were similar.

The developmental rates observed in the warm April of 2018 can be treated as maximal for early spring in central Europe, so long as temperature is the only factor regulating the rate of glochidia development. This latter statement is debatable, however: is the shortening of the brooding period indeed strictly proportional to the change in temperature? The scatter plot of the developmental rates in 2018 (Fig. 2) shows that the developmental rate decreased rapidly during the first brood with temperature, whereas later, no such rapid change within a given group of brooding events was observed. This indicates that the developmental rate in June could be the maximum one allowed by physiological processes. Similar results were reported by Bayne (1965) for Mytilus edulis larvae, the rate of growth of which rose with increasing temperature, although from 13 to $18^{\circ} \mathrm{C}$, growth was relatively temperature-independent.

Global rises in temperature are eliciting ecological responses (Walther et al., 2002), so it is very likely that mussels will react in that their larvae will develop much faster than nowadays. A logical consequence is that they will also increase the number of broods that they can raise during a single season. If we assume that spawning and subsequent brooding are costly to females in terms of energy or specific resources, such as calcium (Silverman et al., 1985), then we should expect that faster development, implying higher rates of metabolism, will exhaust energy reserves or other resources faster, forcing individuals to rest and renew their energy reserves during longer breaks between broods. However, our study did not substantiate this: the length of the time break between consecutive broods did not change much with temperature. It may be that mussels consume energy and/or resources accumulated earlier, although higher temperatures can also accelerate physiological processes and enable females to restore their reserves faster. Moreover, the generally higher production of organic matter in warm environments may provide more resources for breeding in terms of food, but on the other hand, higher 
temperatures may lead to oxygen depletion. At the moment, there are no data on these aspects in relation to $U$. crassus, so present analyses of possible factors and their influences must be speculative. In view of ongoing climate warming, however, research into this problem is very urgent.

Rivers inhabited by $U$. crassus differ with regard to the water depth, channel insolation/shading, water provenance, e.g. supply from ground waters or from surface runoff of rain water. All these factors are related to water temperatures and should influence the mussels' rate of reproduction. However, no striking differences were found between the Biała and San with regard to the onset of reproduction or the shortening of the duration of glochidia brooding during the season or the distribution of larval stages. One of the reasons might be the coarse scale of measurement (one survey per week in the Biała vs one survey every 2 weeks in the San). However, the overlapping distribution of water temperatures in the Biała and San (unpubl. data) suggests that only the general pattern of climate at a large geographical scale have real impact on larval brooding.

After the glaciations, U. crassus most likely recolonized the present-day territory of Poland from the Balkan refuge (J. Sell - pers. comm.). This means that higher water temperatures should not have a serious impact on this species in the central or northern part of its range. It would be worth checking, however, whether its absence in the north of Scandinavia and the British Isles can be attributed to the limiting role of lower water temperatures during spring and summer, thereby decreasing its reproductive output.

\section{Low temperature impacts}

Low temperatures can pose a threat to freshwater mussels, as Heinricher \& Layzer (1999) demonstrated for hypolimnetic discharges from impoundments influencing reproduction in Megolonaias nervosa (Rafinesque, 1820). The females of this species had not been observed to produce glochidia for more than 20 years in its original habitat in the Cumberland River, which was cooled by water release from impoundments. Reproduction was restored after females were translocated to the Tennessee River, with higher water temperatures. Similar effects were reported by Schneider et al. (2018) for gravid females of $U$. crassus, which were kept in captivity at low temperatures and did not release glochidia, whereas gravid females kept at higher temperatures did so during that time. Females observed to postpone glochidia release in cold water released them just as soon as they were transferred to higher temperatures. However, this result may simply be a consequence of the long period of glochidia development in cold water rather than of the active postponement of glochidia release by females. In our study, glochidia brooding took a longer time (mean $=21$ days) than in Schneider's experiment (18 days), after which females were transferred to warmer water, so they could release glochidia at the proper time. This kind of ambiguity can be prevented by the monitoring of larval development stadia.

In our case, lower water temperatures in early spring prolonged the period of glochidia development, which was two (2018) or three (2019) times longer than in the June broods of the same years. This means that in this species, the cooling effect, e.g. that caused by hypolimnetic discharges from impoundments, can reduce by more than half the number of broods raised (when instead of 2 broods per month only one will have enough time to develop), and/or a low water temperature may significantly delay the onset of reproduction (Galbraith \& Vaughn, 2009), with the same consequences for attained fitness.

\section{Conservation}

The rearing of juvenile unionids in captivity has become a widely adopted technique for restoring populations of threatened species (Gum et al., 2011). In order to avoid disturbing gravid females and to ensure effective captive breeding, one should be able to assess with appropriate accuracy at which point in glochidia ontogeny gravid females should be collected. This mode of action was already suggested for Margaritifera margaritifera by Scheder et al. (2011), who developed a simple 5-step key for evaluating $M$. margaritifera larval developmental stages and demonstrated that temperature can modify the rate of glochidia development in this species.

Changing the temperature can be used as a conservation technique, e.g. it might be advantageous for a conservation project to speed up glochidia release or the turnover of brooding events. In such cases, an artificial rise of temperature, after appropriate acclimation, can be used. How to control the influence of 
temperature in natural conditions, e.g. in the case of artificial water cooling, remains an open question. One solution might be to translocate mussels to more favourable functional habitats within the same channel, where temperatures might be higher.

Last but not least is the influence of disturbance in connection with conservation actions or scientific research on glochidia miscarriage (Aldridge \& McIvor, 2003, O'Brien et al., 2013). In our study, $U$. crassus females aborted glochidia in every phase of their embryonic development (see also O'Brien et al., 2013). Thus, the role of $U$. crassus conglutinates as possible bite attracting fish (as in the cases described by Barnhart et al., 2008) is rather doubtful: embryos in the blastula/gastrula stage cannot infest fish. In our study, miscarriage was a rare event: only one-fifth of the broods were miscarried, even though they were so intensively disturbed. The restriction of miscarriage to earlier stages of development may be purely methodological: when examining mussels every other day it is difficult to identify miscarriage in older stages, when only 1-3 days remain to the usual time of release. An ultimate explanation is also possible, namely, that despite disturbance, a female will not abort her almost mature glochidia at the end of brooding, given the very short time remaining for them to be expelled in the usual way.

The exact mechanism of miscarriage and the factors triggering this process still require study. It is thought to be facilitated by oxygen depletion (Aldridge \& McIvor, 2003). Miscarriage is frequently observed during the transportation of gravid females: in our experience, an adequate oxygen supply prevents it (Zajac et al., 2018). Despite the different levels of disturbance in this study, all females were treated in exactly the same way; only some of them aborted glochidia at various stages of development, however, possibly indicating that individual condition might differ and thereby influence miscarriage frequency. A second interesting point is that glochidia were aborted not during handling but later, in the river, where an oxygen deficit is unlikely. The simple, proximate explanation is that embryos were debilitated and/or died during handling when the shell was closed and the amount of oxygen was low. The closed mussel shell prevented embryos from being expelled during handling, and their evacuation in the river was a result of the shell opening and the cessation of brooding already dead larvae.
In conclusion, identification of the developmental stages of glochidia and assessment of the duration of brooding are key ecological data, with eventual payoffs for the conservation of unionids. The duration of brooding may be relatively long, most likely depending on temperature, extending even over 1 month during early spring in comparison to the nearly 1 week development of summer broods. Such differences can have a significant influence on the reproductive output of individuals and populations, depending on the thermal conditions within the water body, resulting from both local anthropogenic impacts (like the release of dammed cold water) and global climate change. U. crassus is an endangered species in Europe, whose protection is regulated by EU law. It is the subject of many active conservation projects, the effective implementation of which must take into account the likely impact of global temperature rise on the methodology of conservation activities. This impact cannot be assessed, and new methods designed, without a thorough knowledge of the impact of seasonal changes, in particular temperature, on reproduction in this species.

Acknowledgements This study was financed by the statutory funds of the Institute of Nature Conservation, Polish Academy of Sciences, and complied with the ethical codes and legal regulations of the Republic of Poland. The authors declare that they have no conflicts of interest.

Open Access This article is licensed under a Creative Commons Attribution 4.0 International License, which permits use, sharing, adaptation, distribution and reproduction in any medium or format, as long as you give appropriate credit to the original author(s) and the source, provide a link to the Creative Commons licence, and indicate if changes were made. The images or other third party material in this article are included in the article's Creative Commons licence, unless indicated otherwise in a credit line to the material. If material is not included in the article's Creative Commons licence and your intended use is not permitted by statutory regulation or exceeds the permitted use, you will need to obtain permission directly from the copyright holder. To view a copy of this licence, visit http://creativecommons.org/licenses/by/4.0/.

\section{References}

Aldridge, D. C. \& D. C. Horne, 1998. Fossil glochidia (Bivalvia, Unionidae): identification and value in palaeoenvironmental reconstructions. Journal of Micropalaeontology 17: 179-182. 
Aldridge, D. C. \& A. L. McIvor, 2003. Gill evacuation and release of glochidia by Unio pictorum and Unio tumidus (Bivalvia: Unionidae) under thermal and hypoxic stress. Journal of Molluscan Studies 69: 55-59.

Aldridge, D. C.; A. Cmiel, A. M. Lipinska, M. Lopes-Lima, R. Sousa, A. Teixeira, K. Zajac, T. A. Zajac, 2018. Remarkable reproductive spurting behaviour of endangered thick shelled river mussel, Unio crassus. In 1st Freshwater Mollusk Conservation Society Meeting in Europe. Verbania, Italy.

Araujo, R. \& M. A. Ramos, 1998. Description of the glochidium of Margaritifera auricularia (Spengler 1793) (Bivalvia, Unionoidea). Philosophical Transactions of the Royal Society of London Series B: Biological Sciences 353: 1553.

Arellano, S. M. \& C. M. Young, 2009. Spawning, development, and the duration of larval life in a deep-sea cold-seep mussel. The Biological Bulletin 216: 149-162.

Barnhart, M. C., W. R. Haag \& W. N. Roston, 2008. Adaptations to host infection and larval parasitism in Unionoida. Journal of North American Benthological Society 27: 370-394.

Bayne, B. L., 1965. Growth and the delay of metamorphosis of the larvae of Mytilus edulis (L.). Ophelia 2(1): 1-47.

Beaty, B. B. \& R. J. Neves, 2004. Use of a natural river water flow-through culture system for rearing juvenile freshwater mussels (Bivalvia: Unionidae) and evaluation of the effects of substrate size, temperature, and stocking density. American Malacological Bulletin 19: 15-24.

Bringolf, R. B., W. G. Cope, M. C. Barnhart, S. Mosher, P. R. Lazaro \& D. Shea, 2007. Acute and chronic toxicity of pesticide formulations (atrazine, chlorpyrifos and permethrin) to glochidia and juveniles of Lampsilis siliquoidea. Environmental Toxicology and Chemistry 26: 2086-2093.

Brodniewicz, I., 1968. On glochidia of the genera Unio and Anodonta from the quaternary fresh-water sediments of Poland. Acta Palaeontologica Polonica 13: 619-628.

Chumnanpuen, P., U. Kovitvadhi, K. Chatchavalvanich, A. Thongpan \& S. Kovitvadhi, 2011. Morphological development of glochidia in artificial media through early juvenile of freshwater pearl mussel, Hyriopsis (Hyriopsis) bialatus Simpson, 1900. Invertebrate Reproduction \& Development 55: 40-52.

Ćmiel, A. M., K. Zając, A. M. Lipińska \& T. Zając, 2018. Glochidial infestation of fish by the endangered thickshelled river mussel Unio crassus. Aquatic Conservation: Marine and Freshwater Ecosystems 28: 535-544.

Ćmiel, A. M., T. Zając, K. Zając, A. M. Lipińska, \& K. Najberek, 2019. Single or multiple spawning? Comparison of breeding strategies of freshwater Unionidae mussels under stochastic environmental conditions. Hydrobiologia, 1-9.

Culp, J. J., W. R. Haag, D. A. Arrington \& T. B. Kennedy, 2011. Seasonal and species-specific patterns in abundance of freshwater mussel glochidia in stream drift. Journal of the North American Benthological Society 30: 436-445

Galbraith, H. S. \& C. C. Vaughn, 2009. Temperature and food interact to influence gamete development in freshwater mussels. Hydrobiologia 636: 35-47.

Gascho Landis, A. M., T. L. Mosley, W. R. Haag \& J. A. Stoeckel, 2012. Effects of temperature and photoperiod on lure display and glochidia release in a freshwater mussel. Freshwater Science 31: 775-786.

Gum, B., M. Lange \& J. Geist, 2011. A critical reflection on the success of rearing and culturing juvenile freshwater mussels with a focus on the endangered freshwater pearl mussel (Margaritifera margaritifera L.). Aquatic Conservation: Marine and Freshwater Ecosystems 21: 743-751.

Haggerty, T. M. \& J. T. Garner, 2000. Seasonal timing of gametogenesis, spawning, brooding and glochidia discharge in Potamilus alatus (Bivalvia: Unionidae) in the wheeler reservoir, Tennessee River, Alabama, USA. Invertebrate Reproduction \& Development 38: 35-41.

Haggerty, T. M., J. T. Garner \& R. L. Rogers, 2005. Reproductive phenology in Megalonaias nervosa (Bivalvia: Unionidae) in wheeler reservoir, Tennessee River, Alabama, USA. Hydrobiologia 539: 131-136.

Hansten, C., M. Heino \& K. Pynnönen, 1996. Viability of glochidia of Anodonta anatina (Unionidae) exposed to selected metals and chelating agents. Aquatic Toxicology 34: $1-12$.

Hastie, L. C. \& M. R. Young, 2003. Timing of spawning and glochidial release in Scottish freshwater pearl mussel (Margaritifera margaritifera) populations. Freshwater Biology 48: 2107-2117.

Heinricher, J. R. \& J. B. Layzer, 1999. Reproduction by individuals of a nonreproducing population of Megalonaias nervosa (Mollusca: Unionidae) following translocation. American Midland Naturalist 141: 140-148.

Hinzmann, M., M. Lopes-Lima, A. Teixeira, S. Varandas, R. Sousa, A. Lopes, E. Froufe \& J. Machado, 2013. Reproductive cycle and strategy of Anodonta anatina (L., 1758): notes on hermaphroditism. Journal of Experimental Zoology 319A: 378-390.

Holman, M. E., 1957. The effect of changes in sodium chloride concentration on the smooth muscle of the guinea-pig's Taenia coli. The Journal of Physiology 136: 569-584.

Jones, J. W., R. A. Mair \& R. J. Neves, 2005. Factors affecting survival and growth of juvenile freshwater mussels (Bivalvia: Unionidae) cultured in recirculating aquaculture systems. North American Journal of Aquaculture 67: 210-220.

Kennedy, T. B. \& W. R. Haag, 2005. Using morphometrics to identify glochidia from a diverse freshwater mussel community. Journal of the North American Benthological Society 24: 880-889.

Kurita, Y., R. Deguchi \& H. Wada, 2009. Early development and cleavage pattern of the Japanese purple mussel, Septifer virgatus. Zoological science 26: 814-821.

Lillie, F. R., 1895. The embryology of the unionidae. A study in cell-lineage. Journal of Morphology 10: 1-100.

Lopes-Lima, M., R. Sousa, J. Geist, D. C. Aldridge, R. Araujo, J. Bergengren, Y. Bespalaya, E. Bódis, L. Burlakova, D. Van Damme, K. Douda, E. Froufe, D. Georgiev, C. Gumpinger, A. Karatayev, Ü. Kebapçi, I. Killeen, J. Lajtner, B. M. Larsen, R. Lauceri, A. Legakis, S. Lois, S. Lundberg, E. Moorkens, G. Motte, K.-O. Nagel, P. Ondina, A. Outeiro, M. Paunovic, V. Prié, T. von Proschwitz, N. Riccardi, M. Rudzīte, M. Rudzītis, C. Scheder, M. Seddon, H. Şereflişan, V. Simić, S. Sokolova, K. Stoeckl, J. Taskinen, A. Teixeira, F. Thielen, T. Trichkova, S. Varandas, H. Vicentini, K. Zajac, T. Zajac \& S. Zogaris, 2017. 
Conservation status of freshwater mussels in Europe: state of the art and future challenges. Biological Review 92: 572-607.

Modesto, V., M. Ilarri, A. T. Souza, M. Lopes-Lima, K. Douda, M. Clavero \& R. Sousa, 2018. Fish and mussels: importance of fish for freshwater mussel conservation. Fish and Fisheries 19: 244-259.

Neves, R. J. \& J. C. Widlak, 1988. Occurrence of glochidia in stream drift and on fishes of the upper North Fork Holston River, Virginia. American Midland Naturalist 119: 111-120.

Nezlin, L. P., R. A. Cunjak, A. A. Zotin \& V. V. Ziuganov, 1994. Glochidium morphology of the freshwater pearl mussel (Margaritifera margaritifera) and glochidiosis of Atlantic salmon (Salmo salar): a study by scanning electron microscopy. Canadian Journal of Zoology 72: 15-21.

O’Brien, C., D. Nez, D. Wolf \& J. B. Box, 2013. Reproductive biology of Anodonta californiensis, Gonidea angulata, and Margaritifera falcata (Bivalvia: Unionoida) in the Middle Fork John Day River, Oregon. Northwest Science 87: 59-73.

Pandolfo, T. J., W. G. Cope, C. Arellano, R. B. Bringolf, M. C. Barnhart \& E. Hammer, 2010. Upper thermal tolerances of early life stages of freshwater mussels. Journal of the North American Benthological Society 29: 959-969.

Raven, C. P., 1958. Morphogenesis: The Analysis of Molluscan Development. Pergamon Press, London: 127-135.

Scheder, C., C. Gumpinger \& D. Csar, 2011. Application of a five-stage field key for the larval development of the freshwater pearl mussel (Margaritifera margaritifera Linné, 1758) under different temperature conditions-a tool for the approximation of the optimum time for host fish infection in captive breeding. Ferrantia 64: 13-22.

Schneider, L. D., P. A. Nilsson \& M. E. Österling, 2018. Evaluating temperature- and host-dependent reproduction in the parasitic freshwater mussel Unio crassus. Hydrobiologia 810: 283-293.

Silverman, H., W. L. Steffens \& T. H. Dietz, 1985. Calcium from extracellular concretions in the gills of freshwater unionid mussels is mobilized during reproduction. Journal of Experimental Zoology 236: 137-147.

Soliman, F. E., A. Y. Moustafa, T. G. Ismail \& O. T. Mohamed, 2016. Reproductive Cycle, Gametogenesis and Embryonic Development of Nitia teretiuscula (Bivaliva: Unionidae), from the River Nile at Sohag Governorate. Egypt. Egyptian Journal of Zoology 174: 1-24.

Taeubert, J. E., G. El-Nobi \& J. Geist, 2014. Effects of water temperature on the larval parasitic stage of the thick-shelled river mussel (Unio crassus). Aquatic Conservation: Marine and Freshwater Ecosystems 24: 231-237.

Walther, G. R., E. Post, P. Convey, O. Hoegh-Guldberg \& F. Bairlein, 2002. Ecological responses to recent climate change. Nature 416: 389-395.

Wang, N., C. G. Ingersoll, D. K. Hardesty, C. D. Ivey, J. L. Kunz, T. W. May, F. J. Dwyer, A. D. Roberts, T. Augspurger, C. M. Kane, R. J. Neves \& M. C. Barnhart, 2007. Acute toxicity of copper, ammonia, and chlorine to glochidia and juveniles of freshwater mussels (Unionidae). Environmental Toxicology and Chemistry: An International Journal 26: 2036-2047.

Wassing, M. \& P. C. Southgate, 2012. Embryonic and larval development of Pteria penguin (Röding, 1798)(Bivalvia: Pteriidae). Journal of Molluscan studies 78: 134-141.

Watters, G. T., \& S. H. O’Dee 2000. Glochidial release as a function of water temperature: beyond bradyticty and tachyticty. In: Freshwater Mollusk Symposia Proceedings, Special Publication of the Ohio Biological Survey, pp. 135-140.

Weaver, L. R., G. B. Pardue \& R. J. Neves, 1991. Reproductive biology and fish hosts of the Tennessee clubshell Pleurobema oviforme (Mollusca: Unionidae) in Virginia. American Midland Naturalist 126: 82-89.

Wood, E. M., 1974. Development and morphology of the glochidium larva of Anodonta cygnea (Mollusca: Bivalvia). Journal of Zoology 173: 1-13.

Zając, K., 2010. Thick-shelled river mussel Unio crassus. In Makomaska-Juchiewicz, M. (ed.), The Monitoring of Animal Species. Guidelines p. I. GIOŚ, Warszawa: 157-179. (in Polish).

Zając, K., J. Florek, T. Zając, P. Adamski, W. Bielański, A. Ćmiel, et al., 2018. On the reintroduction of the endangered thick-shelled river mussel Unio crassus: the importance of the river's longitudinal profile. Science of the Total Environment 624: 273-282.

Publisher's Note Springer Nature remains neutral with regard to jurisdictional claims in published maps and institutional affiliations. 